\title{
Measuring outcomes: one month survival after acute myocardial infarction in Scotland
}

\author{
Simon Capewell, Stephen Kendrick, James Boyd, Geoffrey Cohen, Ed Juszczak, \\ John Clarke
}

\begin{abstract}
Objective-To examine 30 day survival after acute myocardial infarction as an outcome indicator, and explore the effects of adjusting for available prognostic factors such as age, sex, co-morbidity, deprivation, and deaths outside hospital. Design-Cohort study.

Setting-The Scottish Record Linkage System was analysed. This national database links inpatient data to death certificate information for a population of $5 \cdot 1$ million.

Subjects-All 40371 admissions to hospital with a principal diagnosis of acute myocardial infarction, plus all 18452 deaths outside hospital with a principal cause of death registered as acute myocardial infarction (ICD9 code 410) during 1988-1991.
\end{abstract}

Main outcome measures-The outcome event was death from any cause, within hospital or elsewhere, within 30 days of admission.

Results-During 1988-1991, 30 day survival after acute myocardial infarction was $77 \%$ in 40371 hospital admissions, but only 53\% when 18452 acute myocardial infarction deaths in the community were included (a population-based outcome indicator with many advantages). Using logistic regression at an individual patient level, the odds of dying within 30 days effectively doubled for each decade of age (odds ratio compared with patients aged under 55: $2 \cdot 3$ aged 55-64, $4 \cdot 4$ aged $65-74,8 \cdot 2$ aged $75-84,12 \cdot 0$ aged 85 plus); were marginally higher in females than in males (odds ratio 1.07); were almost doubled in patients with a history of previous infarction, coronary heart disease, or other heart disease, and were also significantly increased in patients with circulatory disease, respiratory disease, neoplasm, or diabetes. Socioeconomic deprivation had no significant effect. Marked variations in survival between different hospitals and health board areas persisted, even after adjusting for the above prognostic factors.

Conclusion-One month survival after acute myocardial infarction could be a useful means of measuring outcome of hospital care. There was important geographical variation in one month survival. These differences could be accounted for by variations in referral, admission, diagnosis, definition, and coding. These variables merit further research and local clinical audit before one month survival after acute myocardial infarction can be reliably used for detecting differences in quality of care. In addition, it would be essential to take account of infarct severity.

(Heart 1996;76:70-75)

Keywords: myocardial infarction; coronary heart disease; mortality; prognosis

Each year coronary heart disease kills 17000 Scots, representing $30 \%$ of all male deaths and $25 \%$ of all female deaths. ${ }^{1}$ Half of these deaths are premature, occurring before the age of 75 ; three quarters are due to acute myocardial infarction. ${ }^{1}$ Epidemiological studies have confirmed the high prevalence of coronary heart disease in England ${ }^{2}$ and in Scotland. ${ }^{34}$ Other studies using routine information sources have been less satisfactory for measuring coronary heart disease morbidity. More recently, systematic analysis of hospital data, including deaths after discharge, has become possible with the creation of the Scottish Record Linkage System. ${ }^{5}$

The Clinical Outcomes Working Group of the Clinical Resource and Audit Group has recently published mortality within 30 days of hospital admission for acute myocardial infarction at the level of individual hospital trusts and health board area. ${ }^{6}$ The primary aim was to improve the outcome of clinical care by stimulating discussion about variations between centres. Although geographical variations in survival after acute myocardial infarction were immediately apparent, the report emphasised that crude measures could not be used to make direct inferences about the quality of care. ${ }^{6}$

Survival statistics after acute myocardial infarction are critically dependent on the pre-
Dr S Capewell, 10 Ede Lane, Edinburgh

Accepted for publication 13 February 1996 
cise definitions used, the completeness of case ascertainment, and patient selection (whether all community cases or all hospital admissions or selected admissions). ${ }^{7}$ In population based studies, $50-70 \%$ survive to one month. ${ }^{8-10}$ In contrast, most hospital based studies report a higher one month survival of between $70 \%$ and $90 \% .^{11-13}$ This is because about a quarter of all patients die within one hour of onset of symptoms (sudden deaths) and thus barely $75 \%$ survive long enough to reach hospital. ${ }^{71}$ Following admission, key prognostic factors affecting survival include age, infarct severity, and co-morbidity, ${ }^{9131516}$ and, possibly, socioeconomic deprivation. ${ }^{17} 18$

Factors relevant to survival such as age, sex, prior morbidity, co-morbidity, and aspects of deprivation can be derived from the Scottish national linked data set. ${ }^{5}$ In this study we describe their effect on 30 day mortality.

This paper contributes to the process of refinement and validation of an outcome indicator which is necessary before outcomes monitoring becomes an accurate instrument in assessing the quality of care.

\section{Subjects and methods DATA SOURCES}

In Scotland, all non-maternity, non-psychiatric hospital inpatient and day case discharges are recorded and aggregated nationally as the SMR1 scheme. The application of record linkage techniques permits analysis of the data at the level of the individual patient rather than the episode of care. Linkage of hospital discharge data to Registrar General's death records enables routine follow up in terms of mortality. ${ }^{5}$

\section{METHODS}

The outcome indicator adopted was 30 day mortality after admission to hospital with a principal diagnosis of acute myocardial infarction (ICD9 code 410). For each patient, only the first admission in the three year period was included (October 1988-September 1991). The outcome event was death from any cause, within hospital or elsewhere within 30 days of admission. A three year period was chosen to allow a valid statistical comparison between hospitals.

The SMR1 record allows the coding of the principal diagnosis and up to five other diagnoses. ${ }^{519}$ This presented the opportunity for controlling for the presence of co-morbidity at the time of admission. The linked data set also made it possible to search for any conditions involving admission to hospital in the previous five years. Secondary diagnoses on the index admission and previous conditions were then classified into a limited number of mutually exclusive prior and co-morbidity categories.

In order to examine the effect of socioeconomic deprivation, all cases were assigned to one of five categories based on the deprivation score developed by Carstairs and Morris. ${ }^{20}$

\section{POPULATION-BASED INDICATORS}

In addition to hospital admissions as defined in the individual and hospital level analyses, a case can be made for the adoption of "survival after recognised acute myocardial infarction". This represents an outcome indicator complementary to post-admission survival. The broadening of the analysis beyond those cases of acute myocardial infarction admitted to hospital, required the estimation of a further denominator (referred to as recognised acute myocardial infarction in this paper). This denominator included all deaths outside hospital registered with a principal cause of death of acute myocardial infarction (AMI). This definition excluded those patients who had been admitted for any other condition but who subsequently died of AMI in hospital.

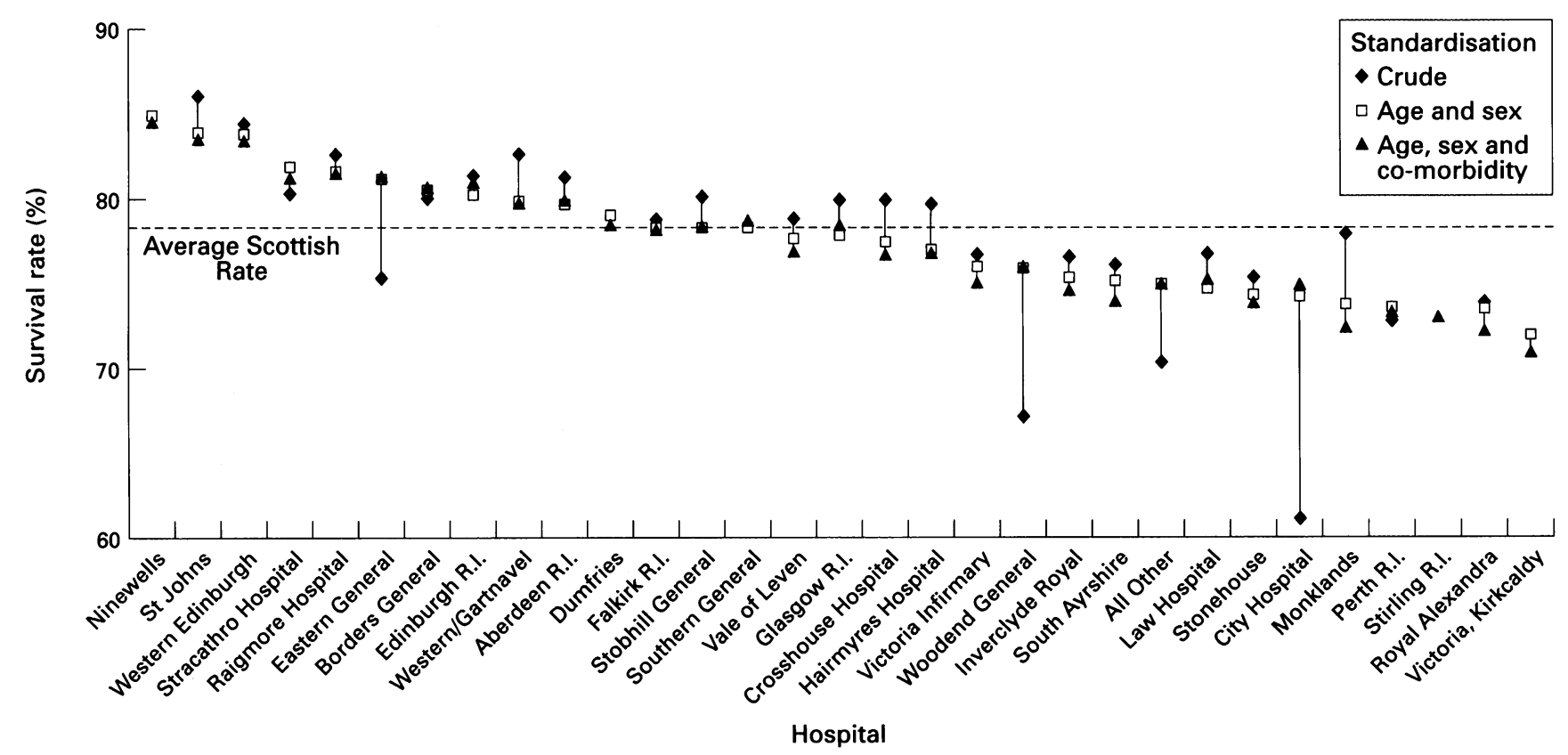

Figure 130 day survival after admission with a principal diagnosis of acute myocardial infarction between October 1988 and September 1991 . Effects of standardisation for (a) age and sex and (b) age, sex, and prior and co-morbidity. 
This enabled the calculation of the following indicators: 30 day survival of all recognised cases of AMI, not just those admitted to hospital; and proportion of recognised AMI cases admitted to hospital. Because of the inclusion of data from death certification these indicators can only be calculated at an area level; Health Board of residence was chosen for our analysis.

\section{STATISTICAL ANALYSIS}

Indirect standardisation was used to adjust hospital-specific 30 day survival rates, first for age and sex differences in the admissions populations and secondly for differences in prior morbidity and co-morbidities and deprivation scores. The outcome measures at hospital level are presented with $95 \%$ confidence intervals as an aid to interpretation, calculated using the square root transform method. ${ }^{21}$

To provide information at an individual patient level a multiple logistic regression model with 30 day mortality as the outcome was used to assess the effect of age, sex, prior morbidity and co-morbidity, and deprivation category. ${ }^{2}$

\section{Results}

Between October 1988 and September 1991, 40371 patients were admitted to Scottish hospitals with a principal diagnosis of acute myocardial infarction. Of these 9097 died

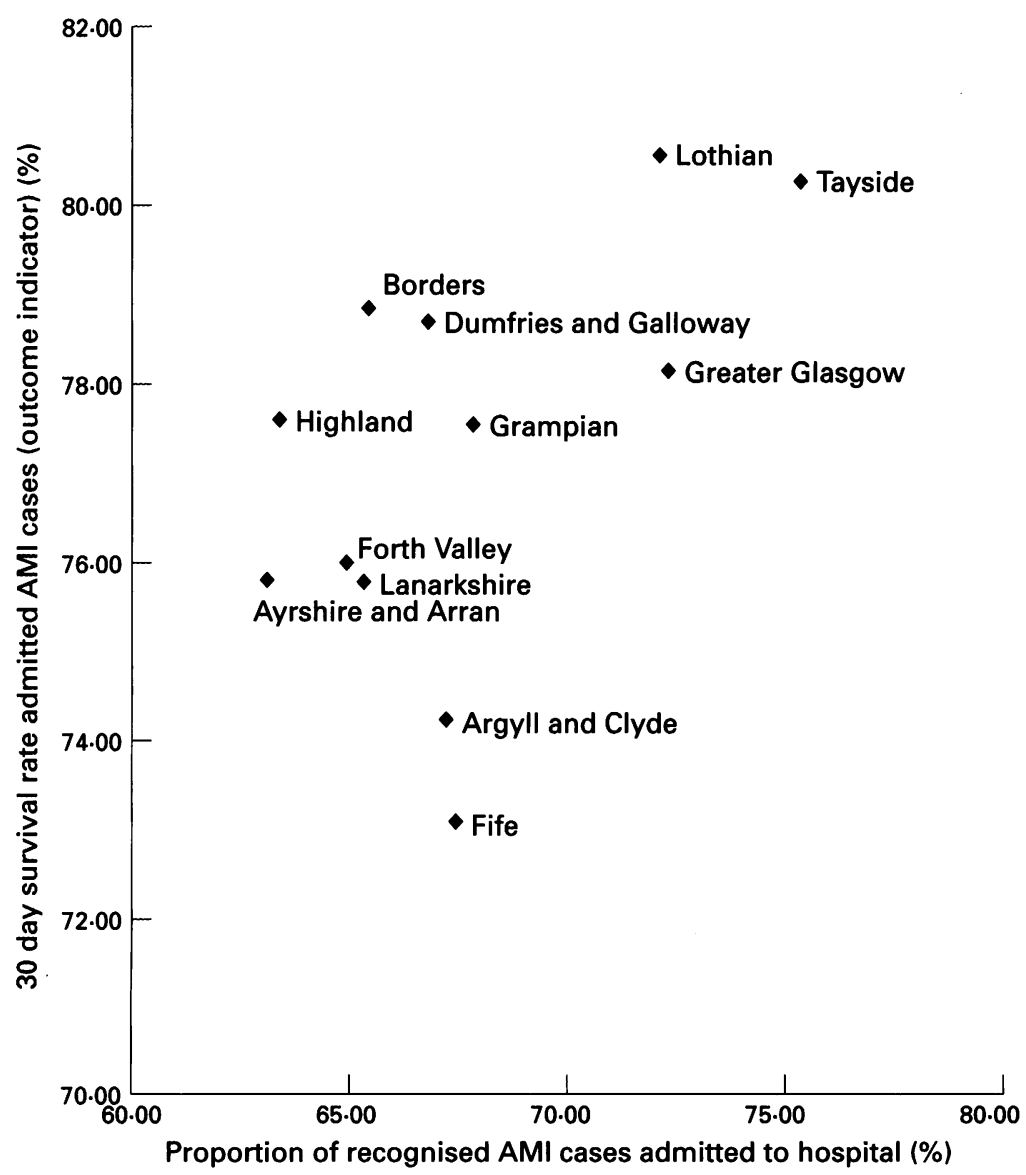

Figure 2 Proportion of recognised AMI cases admitted to hospital plotted against the 30 day survival rate for cases admitted to hospital. within 30 days of admission, giving a one month survival rate after admission of $77 \cdot 5 \%$.

Crude 30 day survival rates varied across hospitals from $61 \cdot 2 \%$ to $85 \cdot 8 \%$ (fig 1 ). Standardisation for age and sex had a marked effect on the survival rates of several hospitals, with standardised survival rates ranging from $71.9 \%$ to $84 \cdot 6 \%$. Figure 1 also shows the effect of adding prior and co-morbidity categories to the standardisation for age and sex. The effects on hospital survival rates were relatively modest. The largest absolute change was 1.29 percentage points; indeed only five out of the 30 effects were larger than $1 \%$. The effect of standardisation for Carstairs deprivation category has not been tabulated; the largest change between the age/sex standardised survival rate and the age/sex/deprivation standardised survival rate involved a shift of only 0.24 percentage points.

At an individual patient level, logistic regression was used with 30 day mortality after hospital admission with AMI as the outcome, to investigate the effect of age, sex, prior and co-morbidity, and deprivation (table 1). All main effects presented are adjusted for all other covariates in the model. Age was a strong influence on the odds of dying within 30 days of hospital admission with AMI. The odds of dying effectively doubled for each decade of age compared with patients aged under 55 (odds ratio: $2 \cdot 3$ aged $55-64 ; 4 \cdot 4$ aged $65-74 ; 8.2$ aged $75-84 ; 12.0$ aged 85 plus). The odds of dying within 30 days were marginally higher in females than in males (odds ratio $1.066 ; 95 \%$ confidence interval 1.012 to $1 \cdot 124$

Compared with patients with no coded prior and co-morbidity, the estimated odds of dying within 30 days were almost doubled in patients with a history of previous infarction (odds ratio $1.74 ; 95 \%$ confidence interval 1.57 to 1.92 ), previous coronary heart disease (odds ratio $2 \cdot 03 ; 95 \%$ confidence interval 1.86

Table 1 Logistic regression analysis: odds of dying within 30 days of admission for $A M I$

\begin{tabular}{lcc}
\hline Coding & Odds ratio & $\begin{array}{l}95 \% \text { Confidence } \\
\text { intervals }\end{array}$ \\
\hline Age: & & \\
Under 55 & 1.00 & \\
55-64 & 2.27 & 2.00 to 2.58 \\
65-74 & 4.41 & 3.91 to 4.98 \\
75-84 & $8 \cdot 19$ & 7.25 to 9.26 \\
85 plus & 11.99 & 10.42 to 13.80 \\
Sex: & 1.00 & \\
Male & 1.07 & 1.01 to 1.12 \\
Female & 1.00 & \\
Prior and co-morbidity: & 1.74 & 1.58 to 1.92 \\
No other condition & 2.03 & 1.86 to 2.22 \\
Previous AMI & 1.83 & 1.69 to 1.98 \\
Other CHD & 1.53 & 1.38 to 1.69 \\
Other heart disease & 1.65 & 1.46 to 1.87 \\
Other circulatory disease & 1.37 to 1.87 \\
Respiratory disease & 1.60 & 1.23 to 1.81 \\
Neoplasm & 1.49 & 1.14 to 1.34 \\
Diabetes & 1.24 & \\
Any other disease & & \\
Deprivation: & & \\
Least deprived & 1.00 & 0.99 to 1.17 \\
& 1.07 & 0.96 to 1.14 \\
& 1.10 & 1.01 to 1.19 \\
Most deprived & 1.06 & 0.98 to 1.15 \\
\hline
\end{tabular}

Odds ratios are adjusted for the remainder of the potential confounders given above. Logistic regression was performed on founders given above. L 
Table 2 Recognised AMI attacks and deaths at Health Board level: October 1988 to September 1991

\begin{tabular}{|c|c|c|c|c|c|c|}
\hline \multirow[b]{2}{*}{ Health Board } & \multirow[b]{2}{*}{$\begin{array}{l}\text { Hospital } \\
\text { admission } \\
\text { for } A M I \\
(A)\end{array}$} & \multirow{2}{*}{$\begin{array}{l}\text { AMI } \\
\text { deaths } \\
\text { without hospital } \\
\text { admission } \\
\text { (B) }\end{array}$} & \multirow{2}{*}{$\begin{array}{l}\text { Proportion } \\
\text { of recognised } \\
\text { AMIs } \\
\text { hospitalised } \\
(A /(A+B))\end{array}$} & \multirow{2}{*}{$\begin{array}{l}\text { Died } \\
\text { within } \\
30 \text { days of } \\
\text { admission } \\
\text { (C) }\end{array}$} & \multicolumn{2}{|l|}{ Survival rates } \\
\hline & & & & & $\begin{array}{l}\text { All recognised } \\
\text { AMIs } \\
(A-C) /(A+B)\end{array}$ & $\begin{array}{l}\text { AMIs } \\
\text { admitted } \\
C / A\end{array}$ \\
\hline Ayrshire \& Arran & 2933 & 1724 & 62.95 & 675 & $48.09 \%$ & $75 \cdot 84 \%$ \\
\hline Borders & 803 & 448 & $65 \cdot 24$ & 194 & $51 \cdot 18 \%$ & $78.89 \%$ \\
\hline Argyll \& Clyde & 3590 & 1750 & $67 \cdot 13$ & 917 & $49 \cdot 89 \%$ & $74 \cdot 17 \%$ \\
\hline Fife & 2504 & 1233 & $67 \cdot 34$ & 679 & $49 \cdot 17 \%$ & $73 \cdot 12 \%$ \\
\hline Greater Glasgow & 7398 & 2790 & $72 \cdot 11$ & 1581 & $56.38 \%$ & $78 \cdot 18 \%$ \\
\hline Highland & 1298 & 779 & $63 \cdot 21$ & 286 & $49 \cdot 77 \%$ & $77.64 \%$ \\
\hline Lanarkshire & 4149 & 2151 & $65 \cdot 15$ & 916 & $49.59 \%$ & $75.79 \%$ \\
\hline Grampian & 3416 & 1674 & $67 \cdot 61$ & 810 & $52.35 \%$ & $77.58 \%$ \\
\hline Orkney & 130 & 117 & $53 \cdot 19$ & 44 & $34.82 \%$ & $66 \cdot 15 \%$ \\
\hline Lothian & 5929 & 2307 & $71 \cdot 86$ & 1171 & $57.71 \%$ & $80.59 \%$ \\
\hline Tayside & 4006 & 1354 & 75.09 & 851 & $59.76 \%$ & $80 \cdot 32 \%$ \\
\hline Forth Valley & 2038 & 1133 & $64 \cdot 75$ & 504 & $49.15 \%$ & $76.00 \%$ \\
\hline Western Isles & 183 & 182 & $51 \cdot 39$ & 58 & $38.85 \%$ & $71.73 \%$ \\
\hline Dumfries \& Galloway & 1385 & 715 & $66 \cdot 58$ & 309 & $52 \cdot 31 \%$ & $78 \cdot 73 \%$ \\
\hline Shetland & 114 & 95 & $55 \cdot 53$ & 31 & $57.62 \%$ & $\mathbf{7 4 . 7 3 \%}$ \\
\hline Scotland & 39876 & 18462 & $68 \cdot 65$ & 9026 & $53 \cdot 19 \%$ & $\mathbf{7 7 . 4 8 \%}$ \\
\hline
\end{tabular}

AMI, acute myocardial infarction.

to $2 \cdot 22$ ), or other heart disease (odds ratio 1.83 ; $95 \%$ confidence interval 1.69 to 1.98 ) and were also significantly increased in patients with circulatory disease, respiratory disease, neoplasm, or diabetes. There was little or no indication that socioeconomic deprivation had a statistically significant effect on the odds of dying within 30 days of admission within this patient population; this finding reinforces the results obtained by the method of standardisation (table 1).

There were 18452 AMI deaths without hospital admission and 39876 with hospital admission for AMI, producing a total of 58328 recognised cases of acute myocardial infarction (table 2).

Figure 2 presents the relation between the post-admission 30 day survival rate standard-

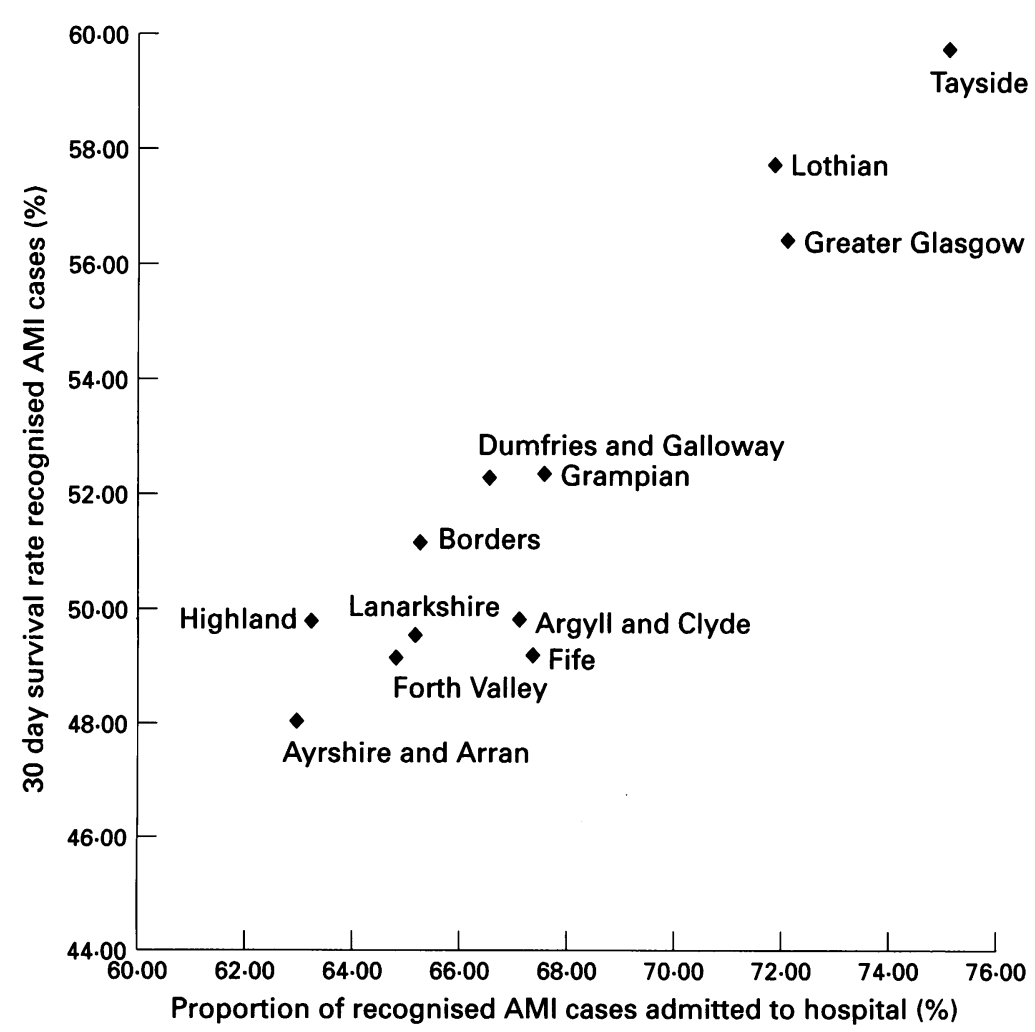

Figure 3 Proportion of recognised AMI cases admitted to hospital plotted against the 30 day survival rate for all recognised cases. ised for age and sex, and the proportion of recognised cases of acute myocardial infarction admitted to hospital.

There seems to be no tendency for health boards that admit a high proportion of recognised cases of AMI to have a lower postadmission survival rate. In particular the three boards which admitted the highest proportions of AMIs to hospital, all had relatively high post admission survival rates. The three, namely Lothian, Greater Glasgow, and Tayside, which seemed to admit a higher proportion of cases to hospital, clearly have the highest 30 day survival in terms of recognised AMI compared with the remaining health boards (fig 3 ).

QUALITY OF DATA

An ISD Quality Assurance Study in 1992 examined a $1 \%$ sample of all SMR1 forms for accuracy of ICD9 coding (Houston, personal communication). Of 199 records with a principal diagnosis of AMI (ICD9 code 410), 190 were correct, nine were incorrect (false positive rate $4 \cdot 4 \%$ ), and a further 13 "true" acute myocardial infarctions were concealed under other codes (false negative rate $6.4 \%$ ). The overall accuracy was therefore $89.2 \%$ $(1-[((9+13) / 203) \times 100 \%])($ table 3$)$.

\section{Discussion}

QUALITY OF DATA

The quality of the administrative data used is crucial to the validity of a study such as this. Completeness and accuracy of death certificates for coronary heart disease are generally

Table 3 Accuracy of ICD9 3-digit coding of principal diagnosis: ISD Quality Assurance Study of $1 \%$ sample Scottish SMR, patients during 1992

\begin{tabular}{lllll}
\hline & $\begin{array}{l}\text { True } \\
\text { number }\end{array}$ & $\begin{array}{l}\text { False } \\
\text { positive }\end{array}$ & $\begin{array}{l}\text { False } \\
\text { negative }\end{array}$ & $\begin{array}{l}\text { Overall } \\
\text { accuracy }\end{array}$ \\
\hline $\begin{array}{c}\text { Acute myocardial } \\
\text { infarction }\end{array}$ & 203 & $4 \cdot 4 \%$ & $6 \cdot 4 \%$ & $89 \cdot 2 \%$ \\
$\quad$ (ICD9 code 410) & 74 & $1 \cdot 4 \%$ & $6 \cdot 8 \%$ & $92 \%$ \\
$\begin{array}{c}\text { Fractured neck } \\
\text { of femur } \\
\text { (ICD9 code 820) }\end{array}$ & 7139 & $4 \cdot 3 \%$ & $10 \cdot 8 \%$ & $85 \%$ \\
$\begin{array}{c}\text { Stroke } \\
\quad \text { ICD9 codes }\end{array}$ & & & & \\
$\quad 430-434,436-438)$ & & & & \\
\hline
\end{tabular}


good. ${ }^{71422}$ SMR1 hospital inpatient records are essentially complete and about $94 \%$ accurate for the diagnosis and coding of principal diagnosis in general, and $89 \%$ accurate specifically for acute myocardial infarction (table 3; Harley personal communication and Pears et $\left.a l^{23}\right)$. Recording of secondary diagnoses on the SMR1 form is relatively poor, ${ }^{19}$ therefore the main source for establishing prior morbidity in our study was the presence of principal diagnosis in both previous SMR1 episodes and prior cancer registrations. The odds ratios (relative risk) associated with prior and co-morbidities in the individual analysis were very similar to other studies. ${ }^{91213}$

EFFECTS AT THE HOSPITAL LEVEL

Standardisation for age and sex produced marked changes in outcome for some hospitals. Further standardisation for prior and comorbidities and deprivation respectively had little effect on survival at hospital level (fig 1).

\section{INDIVIDUAL CORRELATES OF SURVIVAL}

Although over 50 prognostic factors are described in AMI, multivariate analyses reveal that four are dominant: infarct severity, age, pre-existing disease, ${ }^{121315}$ and patient selection. ${ }^{79}$

Only the latter three can be derived from the available administrative data. In Scots patients, the main determinants of the odds of dying within 30 days of admission for AMI were age, prior and co-morbidity, and sex. These findings accord closely with previous hospital based ${ }^{91315}$ and population-based studies. ${ }^{10}$ There was little or no evidence that socioeconomic deprivation had any effect. Larger effects have been reported in other studies using a longer follow up period. ${ }^{17} 18$

\section{POPULATION-BASED SURVIVAI}

A quarter of all infarct patients die within the first hour and more within the next 24 hours. $^{71424}$ In our series, $67 \%$ of deaths occurred without hospital admission, similar to Belfast, Glasgow, and elsewhere. ${ }^{14} 22$ The $77 \%$ survival in hospital patients and $53 \%$ population-based survival accord closely with other studies. ${ }^{8-1325}$ The latter population-based measure is less vulnerable to selection bias and may represent a useful "global" measure of value to purchasers.

It had been suggested that those health boards that were quickest at getting heart attack cases to hospital might be penalised in terms of worse post-admission survival rates. In fact, our data suggest the opposite-survival was highest in the three health boards admitting the highest proportion of recognised acute myocardial infarctions (figs 2 and 3 ). All three, Greater Glasgow, Lothian, and Tayside are teaching health boards with largely urban populations. The definition of acute myocardial infarction may vary substantially between hospitals and health boards, as seen in the USA and Scandinavia. ${ }^{26} 27$

As diagnostic tests become more sensitive and more frequently performed on larger numbers of patients, so the increasing propor- tion of milder AMI cases diagnosed may "dilute" patient groups and expand the denominator, with apparent improvements in survival. ${ }^{26} 27$ Any such variation between hospitals in admission and diagnostic thresholds would lead to variation in the mean severity of disease in the patients admitted. Infarct severity has a 20 to 50 fold effect on mortality. ${ }^{12}{ }^{1315}$ In contrast, treatment effects are relatively modest, reducing mortality by 20 to $30 \%{ }^{28}$ The potential impact of revascularisation after infarction seems similarly limited. ${ }^{29} 30$

This study has been able to address the effects on survival of aspects of case mix which can be derived from routine administrative data such as age, coded co-morbidity and prior morbidity, and deprivation. Prospective disease registers offer one option to facilitate valid outcome comparisons. ${ }^{7}$ Conversely, differences in quality of care between hospitals may be better detected by process measures. ${ }^{31}$ However, estimates such as Mant and Hicks' ${ }^{32}$ rely heavily on assumptions that all treatment interventions have been identified and that in each case their precise effects in routine clinical practice are known. In reality, process and outcome measures will probably remain complementary audit tools for a long time. ${ }^{6}$

One month survival after acute myocardial infarction could be a useful means of measuring outcome of hospital care. We have found important geographical variation in one month survival. However, these differences could be accounted for by variations in referral, admission, diagnosis, definition, infarct severity and coding. These variables merit further research and local clinical audit ${ }^{67}$ before one month survival after acute myocardial infarction can be reliably used for detecting differences in quality of care.

We thank Dr Mary Fulton, Professor AR Lorimer, Dr I Findlay, and $\mathrm{Dr} D$ Moir for advice and encouragement and Mrs Anne Garrett and Ms Sarah Duguid for typing the manuscript. SC was employed by the Scottish Office Home and Health Department until 1995. The views expressed are the authors' and do not necessarily reflect those of the Information and Statistics Division, nor the Scottish Office Home and Health Department.

1 Scottish Office Department of Health. Coronary heart disease in Scotland. Report of a policy review. Edinburgh: HMSO, 1996;13-6.

2 Shaper AG, Pocock S, Walker M, Phillips AN, Whitehead TP, MacFarlane PW. Risk factors for ischaemic heart disease: The prospective phase of the British Regional Heart Study. $\mathcal{f}$ Epidemiol Community Health 1985;39: 197-209.

3 Smith WCS, Kenicer MB, Tunstall-Pedoe H, Clark EC, Crombie IK. Prevalence of coronary heart disease in Scotland: Scottish Heart Health Study. Br Heart $f$ 1990;64:295-8

4 Isles CG, Hole DJ, Hawthorne VM, Lever A. Relation between coronary risk and coronary mortality in women of the Renfrew and Paisley survey in comparison with men. Lancet 1992;339:702-6.

5 Kendrick S, Clarke J. The Scottish Record Linkage System. Health Bull (Edinb) 1993;51:72-9.

6 CRAG: Clinical Resource and Audit Group, the Clinical Outcomes Working Group. Clinical outcome indicators. Outcomes Working Group. Clinical outcome indicators. Edinburgh: Sco

7 Tunstall-Pedoe $\mathrm{H}$. Monitoring $\mathrm{CHD}$ in the community: why and how? In: Marmot $\mathrm{M}$, Elliot $\mathrm{P}$, eds. $C H D$
why why and how? In: Marmot $\mathrm{M}$, Elliot $\mathrm{P}$, eds. CHD Epidemiology from aetiology to public health.

8 Jackson R, Stewart A, Beaglehole R. Trends in CHD mortality and morbidity in Auckland, New Zealand tality and morbidity in Auckland, New

9 Martin CA, Thompson PL, Armstrong BK, Hobbs MST Long term prognosis after recovery from myocardial infarction: a nine year follow-up of the Perth Coronary 
Register. Circulation 1983;68:961-9.

10 Nayha S. Improved survival after AMI in Finland 1974-1985. Int $\mathcal{F}$ Epidemiol 1992;21:30-5.

11 M conds in survival of hospitalised MI patients between 1970 and 172- The Minnesota Heart Survey. Circulation 1992;85: $172-9$

12 Udverhelyi IS, Gatsonis C, Epstein AM, et al. AMI in the Medicare population. Process of care and clinical out comes. 7 Am Med Ass 1992;268:2530-6.

13 Stevenson R, Ranjadayalan K, Wilkinson P, Roberts R, Timmis AD. Short and long term prognosis of acute myocardial infarction since introduction of thrombolysis. BrMed f 1993;307:349-53.

14 Fitzpatrick B, Watt GCM, Tunstall-Pedoe H. Potential impact of emergency intervention on sudden deaths from CHD in Glasgow. Br Heart $\mathcal{f}$ 1992;67:250-4.

15 Norris RM. Brandt PWT, Lee AJ. Mortality in a coronary care unit analysed by a new coronary prognostic index. Lancet 1969;i:278-81.

16 Parsons RW, Jamrozik UD, Hobbs MST, Thompson DC Early identification of patients at low risk of death afte myocardial infarction and potentially suitable for early hospital discharge. Br Med f 1994;308: 1006-10.

17 Kottke TE, Young DT, McCall MM. Effect of social class on recovery after myocardial infarction. Minn Med 1986; 63:590-7.

18 Tofler GH, Muller JE, Stone PH, Davies G, Davies VG, Braunwald E. Comparison of long term outcome after acute myocardial infarction in patients never graduated from high school with that in more educated patients. MILIS. Am F Cardiol 1993;71:1031-5.

19 Kohli HS, Knill-Jones RP. How accurate are SMRI (Scottish Morbidity Record 1) data? Health Bull (Edinb) (Scottish Morbidit

20 Carstairs V, Morris R. Deprivation and health in Scotland. erdeen: Aberdeen University Press, 1991;14-42.

21 Breslow NE, Day NE. Statistical methods in cancer research.
Volume II. The design and analysis of cohort studies. Lyon: IARC, 1987;11-5.

22 McIlwaine WJ, Domnelly $M$, Chivers AT, Evans $A E$ Elwood JH. Certification of death from IHD in Belfast.

23 Pears J, Alexander V, Alexander GF, Waugh NR. Audit of the quality of hospital discharge data. Health Bull (Edinb) the quality of ho

24 Colling A, Dellipiani AW, Donaldson RJ, McCormack P. Teeside Coronary Survey. An epidemiological study of acute attacks of myocardial infarction. $\mathrm{Br}$ Med f 1976;

25 Evans AE, Patterson CC, Mathewson Z, McCrum EE, Mcllmoyle EL. Incidence delay and survival in the Belfast MONICA project coronary event register. Rev Epidemiol Sante Publique 1990;38:419-27.

26 Hammar N. Larsen FF, Sandberg E, Alfredsson L Theorell $T$. Time trends in survival from $M I$ in Stockholm County 1976-1984. Int $\mathcal{f}$ Epidemiol. 1992 21:1090-6.

27 Edlavitch SA, Crow R, Burke GL, Baxter J. Secular trends in $Q$ wave and non- $Q$ wave AMI. The Minnesota Heart Survey. Circulation 1991;83:492-503.

28 Lau J, Antman EM, Jimenez-Silva J, Kupelnick B, et al. Cumulative meta-analysis of therapeutic trials for myocardial infarction. N Engl f Med 1992;327:248-54.

29 Pilote L, Califf RM, Sapp S, et al. Regional variation across the United States in the management of acute myocardial infarction. N Engl $¥$ Med 1995;333:565-72.

30 Guadagnoli E, Hauptman PJ, Ayanian JZ, et al. Variation in the use of cardiac procedures. $N$ Engl $f$ Med 1995; 333:573-8.

31 Hampton JR, McWilliam A. Purchasing for quality; the providers view. Purchasing care for patients with AMI providers view. Purchasing care for
Quality in Health Care 1992;1:68-73.

32 Mant J, Hicks N. Detecting differences in quality of care: the sensitivity of measures of process and outcome in treating acute myocardial infarction. Br Med f 1995;311:793-6. 